\title{
Atuação política da classe empresarial: um estudo de caso sobre a Federação das Indústrias do Estado de Santa Catarina
}

\author{
Keylla Thais Signorelli ${ }^{*}$ \\ Silvio A. F. Cario ${ }^{* *}$
}

\begin{abstract}
Resumo
O objeto da pesquisa é a atuação política do empresariado nacional, representado pela Federação das Indústrias do Estado de Santa Catarina (FIESC), maior entidade de representação da classe empresarial no estado. Para isto, realizou-se uma revisão de literatura, além da pesquisa documental com dados disponibilizados pela FIESC e pelo Tribunal Superior Eleitoral. Primeiramente, apresenta-se o campo teórico a respeito da ação da elite orgânica na condução da hegemonia dominante no interior dos aparelhos do Estado, destacando o processo político como ferramenta de poder. Em seguida, recuperase sinteticamente a trajetória histórica do empresariado como ponta do tripé do desenvolvimento nacional. Por fim, estreitando o objeto do estudo, verifica-se na atuação da FIESC um forte ator político em Santa Catarina. Representante do empresariado industrial, atende os interesses de classe através de sua forte influência no setor público e na sociedade civil. As principais ações nas últimas gestões foram: liderança no movimento pela redução dos impostos, iniciativas voltadas a uma maior inserção da indústria no comércio mundial, auxílio ao governo estadual na elaboração de estudos sobre rotas estratégicas de desenvolvimento industrial, capacitação de empresários e trabalhadores em cursos e palestras, realização de estudos colaborativos com universidades e institutos de pesquisa, entre outros.
\end{abstract}

Palavras-chave: Estado; empresariado; FIESC

\section{Political activities of the business class: a case study on the Federação das Indústrias do Estado de Santa Catarina}

\begin{abstract}
The subject of this research is the political activity of the national business class, represented by the Federação de Indústrias do Estado de Santa Catarina (FIESC), the largest representative entity of the business class in Santa Catarina. To this end, a literature review was carried out and then a data investigation was conducted in the database provided both by FIESC and the Tribunal Superior Eleitoral. Firstly, it is presented the theoretical field of the organic elite's action in conducting the dominant hegemony inside the State apparatus, highlighting the political process as a power tool. Then, the historical trajectory of the business community is briefly approached as being one end of the national development tripod. Finally, considering its initiatives, FIESC is seen as a strong political actor in Santa Catarina. Representing the industrial business community, it serves the interests of that class through its strong influence in the public sector and the civil society. The main actions during the last administrations were: leadership in the movement to reduce taxes, initiatives aiming at a greater insertion of industry in world trade, aid to the state government in the elaboration of studies on strategic routes of industrial development, training of entrepreneurs and employees in courses and lectures, collaborative studies with universities and research institutes, among others.
\end{abstract}

Keywords: State; business class; FIESC

JEL Classification: D02, Z13

\footnotetext{
* Graduada no Curso de Ciências Econômicas pela Universidade Federal de Santa Catarina. Email: keyllasignorelli@gmail.com

* * Professor do Depto. de Economia e Relações Internacionais da Universidade Federal de Santa Catarina. E-mail: fecario@yahoo.com.br
} 


\section{Introdução}

Dentro do sistema capitalista de produção, a influência da classe empresarial sobre a atividade econômica é expressivamente relevante. Cabe ao poder público interferir nessa relação com o empresariado, promovendo a sua confiança, em especial de uma elite orgânica. Tal elite é composta principalmente por proprietários e executivos de empresas de grande porte, cujas decisões econômicas exercem forte impacto sobre a sociedade. Segundo interpretação de Mancuso (2007), os empresários do setor privado são incumbidos de tomar decisões no que se refere à produção e distribuição de bens e serviços, exercendo impacto sobre toda a sociedade. As decisões da classe afetam o nível e a qualidade de empregos, preços, crescimento econômico e o padrão de vida num determinado momento.

A classe empresarial se preocupa com bons arranjos institucionais na economia, de forma que o poder público se mostra preocupado em atender, se não todos, ao menos parte de seus interesses. Se as decisões contrariarem os interesses dos empresários, a classe irá se desmotivar a investir, e sem investimentos não há produção e geração de empregos. Assim, a chance de reeleição dos políticos que estão no exercício do poder diminui, porque as consequências negativas do declínio da atividade empresarial serão atribuídas à incapacidade dos políticos para garantir o bom funcionamento do sistema econômico. Portanto, é vital ao Estado manter boas relações com o empresariado, seja por meio de seus sindicatos patronais ou pelos órgãos federativos de representação.

No caso específico do Brasil, o Estado favoreceu a ação coletiva da classe empresarial, fundindo, por vezes, os âmbitos público e privado. Exemplo dessa relação tão próxima ocorre no Estado de Santa Catarina, onde a maior Federação representante da classe patronal ligada à indústria é a principal fonte de informações econômicas e estatísticas para o estado. A Federação das Indústrias do Estado de Santa Catarina (FIESC) é uma entidade chave na relação entre Estado e esfera privada, e desde sua fundação os seus dirigentes mantiveram uma colaboração muito estreita com as autoridades governamentais.

Desse modo, o objeto desse estudo envolveu identificar dentro da estrutura da FIESC as articulações políticas do empresariado catarinense, a fim de favorecer a compreensão do impacto de suas articulações para essa classe e a sociedade. A estrutura do trabalho está composta por 4 seções. A seção 1 apresenta o tema de forma introdutória, e a seção 2 aborda aspectos da autonomia relativa do Estado, destacando a funcionalidade dos intelectuais orgânicos no seio da sociedade. A seção 3 descreve sinteticamente a atuação política da classe empresarial brasileira. A seção 4 analisa as articulações políticas do empresariado catarinense 
por meio do maior órgão de representação da classe no estado. E, por fim, a seção 5 compreende as principais conclusões da pesquisa.

\section{Tratamento teórico: Estado e empresariado}

O Estado, emergindo das relações de produção, revela uma verdadeira expressão política da estrutura de classe inerente à produção. Cumpre-lhe uma função de condensador e organizador das classes no interior dos seus aparelhos. "A autonomia dá lugar à luta de classes no Estado e à possibilidade das classes dominadas tomarem os aparelhos do Estado, para seus próprios propósitos e interferirem nas funções do Estado que reproduzem o domínio dos grupos dominantes" (CARNOY, 1998, p. 141). O Estado ocupa um papel central, de organizador e unificador da burguesia do bloco no poder, na medida em que mantém sua autonomia relativa com relação a tal fração e a componentes desse bloco. Nas palavras de Nicos Poulantzas, "[...] o Estado não é pura e simplesmente uma relação, ou a condensação de uma relação; é a condensação material e específica de uma relação entre classes e frações de classe" (POULANTZAS, 1978, p. 148).

Nesses termos, a característica da autonomia relativa faz do Estado o espaço de dominação política, em que não necessariamente a dominação política é assegurada pela dominação econômica. A autonomia relativa permite uma atuação mais autônoma de interesses específicos, podendo contemplar setores da economia que não detenham todos os setores do capital. Logo, a intervenção do Estado identifica, sobretudo, sua função econômica na medida em que intervém no processo de acumulação do capital. Portanto, obter o poder político é uma das ferramentas para alcançar o domínio da sociedade. É por meio da conquista do poder político que se materializam os interesses da classe dominante e seus objetivos. Em termos de sociedade capitalista, a conquista da política se torna um espaço necessário para a recriação das condições de reprodução do sistema, seja por meio da valorização de capital, que está interessado na reprodução material, ou também pela capacidade intelectual dessa relação de produção.

No contexto das relações hegemônicas, a orientação política e cultural de uma classe social sobre a sociedade se realiza pela mediação dos intelectuais. Esses intelectuais exercem funções em todos os campos das relações sociais, organizando a economia, a cultura, a política, as ideologias, viabilizando assim o exercício da hegemonia. Um autor central que discute o conceito de hegemonia e o papel dos intelectuais orgânicos como reguladores e mediadores do poder hegemônico é o italiano Antônio Gramsci. Conforme a visão gramsciana, a conquista do poder hegemônico representa a base para sustentação e legitimação da ordem social, moldadas 
pelos interesses da classe dominante. Por outro lado, a hegemonia, para as classes dominadas, apresenta-se como uma necessidade histórica de superar as divisões sociais, unir forças populares e lutar por uma nova ordem social. Dessa forma, é no âmbito das relações hegemônicas que se formam os intelectuais orgânicos da sociedade. Sejam eles representantes da burguesia ou da classe proletária, expressam, organizam, defendem os objetivos e interesses do grupo social ao qual estão vinculados.

Gramsci afirma que o partido político é "[...] o mecanismo que realiza na sociedade civil a mesma função desempenhada pelo Estado, de um modo mais vasto e sintético, na sociedade política, ou seja, proporciona a soldagem entre intelectuais orgânicos de um dado grupo, o dominante, e intelectuais tradicionais" (GRAMSCI, 2006, p. 25) O partido político cumpre um importante papel na esfera da sociedade civil, exercendo uma função orgânica no seio do Estado, que é esfera da sociedade política. Nos países capitalistas avançados, onde a sociedade civil é mais complexa e organizada, o partido político torna-se a instituição capaz de estimular a formação de uma vontade coletiva, podendo iniciar uma reforma intelectual e moral na sociedade, uma vez que é um órgão de manifestação pública.

Com o processo de internacionalização na escala mundial, os limites entre Estado nacional e sociedade civil adquirem um novo carácter. Inserida dentro dos aparelhos do Estado capitalista, a classe empresarial desenvolve um papel central na coordenação do Estado. Como ator político, mostra um elevado grau de coesão nas articulações políticas, por meio da capacidade e técnica, e influencia o campo político à procura de resultados econômicos. Para Gramsci (2006), essa influência exerce as funções de dominação e de hegemonia da superestrutura. A força exercida pela hegemonia passa a ser revestida, nesse processo, pelo elemento da coerção. Gramsci afirma que, “[...] o empresário capitalista cria consigo o técnico da indústria, o cientista da economia política, o organizador de uma nova cultura. O empresário cumpre o papel de organizador de massa de homens, gerando confiança dos investidores e de seus consumidores" (GRAMSCI, 2006, p. 17). Para o autor, se não toda a elite, ao menos uma parte dela deve possuir a capacidade de organização da sociedade, num complexo organismo de serviços, dos quais se criam condições necessárias para a própria expansão de classe. "Se não todos os empresários, tecno-empresários intelectuais, burocratas e militares, ao menos uma elite entre eles deverá ter a capacidade de articular e organizar os seus interesses" (DREIFUSS, 1987, p. 24).

Para classificar a ação dessa elite empresarial, é preciso identificar em primeira instância sua "Elite Orgânica". Segundo definição de Dreifuss, “[...] a elite orgânica é composta de agentes coletivos político-ideológicos especializados no planejamento estratégico e na 
implementação da ação política de classe, através de cuja ação se exerce o poder de classe" (DREIFUSS, 1987, p. 24). A diferenciação da elite orgânica do conjunto da classe dominante ocorre no processo de liderança que essa impõe sobre as demais classes, operando como fator de poder político. Embora organicamente vinculada ao seu universo social, econômico e cultural, esta diferenciação é imprescindível para uma intervenção política eficaz e eficiente, na medida em que a classe dominante é única na sua diversidade de unidades de acumulação competitivas (seja no nível da composição e capital, no plano da produção setorial ou no universo dos grupos econômicos), às quais correspondem essencialmente percepções e atitudes corporativas ou de solidariedade expressas em associações, sindicatos ou federações de classe (DREIFUSS, 1987).

Comportando-se como mediadoras no bloco de poder, as elites orgânicas predispõem a classe dominante para a luta política. Essa elite, a fim de exercer sua posição de liderança na sociedade, e influenciar na esfera da produção, usa a ação política para alcançar sua realização constitucional. Nas palavras de Dreifuss, “[...] a articulação entre produção e instituição, entre economia e Estado, entre estrutura e superestrutura, se dá pela luta política dos interessados" (DREIFUSS, 1987, p. 25). Dessa forma, a política se torna uma ação permanente e gera, por meio dela, organizações permanentes na medida em que se identifique com a economia.

A elite orgânica, através do seu discurso para o conjunto das classes dominantes, se apresenta na sociedade como um agente ideológico e político, influenciando, por meio de sua atuação, a própria organização do Estado. Ela é a parcela intelectual da burguesia, que atua como mentora intelectual da classe que representa, sendo a autoconsciência cultural e política e o núcleo de autocritica da classe dominante. "A elite orgânica produz estudos, análises e pesquisas sobre os princípios da política pública e da política empresarial, formulando diretrizes que deverão nortear o funcionalmente da sociedade e do Estado" (DREIFUSS, 1987, p. 27). Atuando como núcleo esclarecido, é capaz de manter sua influência intra e entre classes, em decorrência de sua homogeneidade e consistência. No interior da classe dominante, age no sentido de promover a coesão interna da classe. Do mesmo modo, trabalha através de seus recursos para que essa classe se posicione a favor de seus projetos. Por isso, a elite orgânica é associada à ação política organizada e planejada, e isso corre por meio de táticas e estratégias de cunho político e ideológico.

Portanto, segundo o conceito, a elite orgânica pode ser definida como o conjunto de agentes articulados política e ideologicamente, cuja atuação é estrategicamente especializada no planejamento e na implementação da ação política de classe. Para Dreifuss (1987), a elite 
orgânica não apenas se encarrega do planejamento estratégico da ação política, como também atua na articulação do conjunto de ações, táticas e manobras.

\section{Estado e empresariado nacional}

O Estado cumpriu um importante papel na industrialização do Brasil. Articulou, formulou e executou políticas para o desenvolvimento econômico, tecnológico e social. Por muitas vezes, foi o indutor do padrão de ação coletiva da classe empresarial, sendo exemplo disso as federações empresariais que atuam em conjunto com o governo. Em virtude de sua função histórica, assumiu um alto grau de autonomia em relação à sociedade, tornando-se assim o locus privilegiado dos conflitos sociais. Os primórdios do complexo exportador cafeeiro deram suporte e condições necessárias para a transformação na economia brasileira por meio de sua acumulação de capital e o auge do nível de exportação. No campo político, como aponta Diniz (1978), a mudança se expressava pelas novas elites identificadas com a implantação do capitalismo industrial, possibilitando, no campo econômico, a criação de toda uma infraestrutura, assim como mecanismos institucionais voltados para dar suporte ao crescimento do setor industrial. Na ausência de uma arena política plenamente democrática, o interior de seus aparelhos foi usado como expressão dos interesses dominantes para competir, expressar e atender interesses.

Embora o setor agrário tivesse a maior representação para o projeto desenvolvimentista brasileiro, a partir da década de 1940 até meados da década de 1960, verifica-se que o setor industrial precisava se articular contra o esgotamento do processo de substituição de importações e as pressões dos movimentos sindicais. No entanto, o empresariado industrial nacional não poderia, por si só, afrontar os problemas de industrialização pesada, uma vez que sua produção estava ancorada nas indústrias leves e com frágil poder de acumulação. "Sua fraqueza política, que correspondia à sua fragilidade econômica, retirava-lhe qualquer esperança de 'privatizar' no futuro o Estado. Por isso mesmo, o capital industrial nacional 'optou' pela entrada do capital estrangeiro nos novos setores e pelo papel relativamente limitado do Estado como empresário" (MELO, 1998, p. 127).

O que se pode afirmar, conforme Draibe (2004), é que até o momento do Estado Novo, o projeto de industrialização pesada não havia ganhado consistência, nem havia sido definida a forma de articulação entre os gastos do Estado e do setor privado com relação aos novos projetos de industrialização. Dreifuss (1981), descreve que a estratégia da burguesia empresarial agiu dentro dos aparelhos do Estado, renovando acordos por meio das associações de classe empresariais, como a Federação das Indústrias do Estado de São Paulo (FIESP), o 
Centro das Indústrias do Estado de São Paulo (CIESP) e a Associação Comercial do Rio de Janeiro (ACRJ). Assim, em busca de participação no Executivo, a elite intelectual usou de modos antipopulistas para atender seus interesses de classe.

A década de 1980 representou uma tendência inversa com relação aos anos anteriores, pois, com o declínio do crescimento econômico e os fluxos financeiros instáveis, foram restringidos drasticamente os recursos advindos sobre forma de empréstimo ou investimentos do capital internacional. Em decorrência disso, temos um país em profunda recessão econômica e sérios problemas estruturais. A disseminação do pensamento neoliberal representou no Brasil a consolidação da hegemonia mundial do neoliberalismo. Por meio do Consenso de Washington, os Estados Unidos e, posteriormente, o Fundo Monetário Internacional (FMI) adotaram as medidas recomendadas como obrigatórias para fornecer ajuda aos países em crises e negociar as dívidas externas. Dessa forma, o governo brasileiro adotou, principalmente na década de 1990, uma agenda de reformas econômicas e constitucionais, de modo a possibilitar a retomada do crescimento econômico, controlando a inflação e dando credibilidade financeira ao país. Para dar estabilidade econômica e confiança aos investidores e ao empresariado transnacional, a economia foi orientada pela abertura de mercado.

A estabilização econômica promovida pelo plano real atendia em partes as demandas do país. Aos industriais, possibilitava previsibilidade quanto aos planos de investimentos, contudo, essas dependiam de dois fatores: estabilidade econômica e mercado consumidor. No que tangencia ao interesse do empresariado industrial, as medidas alteraram pouco os problemas financeiros vivenciados pela fração interna da classe, a qual perdia mercado e se enfraquecia frente à competitividade internacional. Mesmo afetado pela política econômica implementada, o empresariado industrial, com receio da postura de Lula, apoiou sem hesitação a candidatura de Fernando Henrique Cardoso (1995-2002) para o cargo de Presidente da República. Contando com o apoio de Itamar Franco, o candidato venceu as eleições e assumiu o cargo no ano de 1995.

De uma maneira geral, parte do empresariado atingido pela liberalização econômica manifestou-se contrário às medidas que foram adotadas nos governos de Fernando Henrique Cardoso (FHC). Enquanto uma parcela do empresariado nacional se beneficiou com as novas diretrizes econômicas, a grande maioria perdeu mercado, devido à forte concorrência internacional ou por meio das fusões e aquisições, com estratégias empresariais para se manter no mercado. Portanto, a política do governo FHC visava abrir a economia para o mercado externo como estratégia para modernização da economia brasileira, e em contrapartida não 
apresentava ter maiores preocupações com a elevada exposição das empresas brasileiras nesse cenário de reformas.

Com relação às profundas mudanças no cenário político de 2002, “[...] reacende o debate em torno da retomada do desenvolvimento, num processo em que a convergência das propostas das principais entidades empresariais aparece como um elemento central" (DINIZ; BOSCHI, 2000, p. 17). Lula buscou em seu governo manter uma base aliada com a classe empresarial, aliando-se ao Partido Liberal (PL), tendo o senador e empresário José Alencar, do setor têxtil, como seu vice-presidente. O governo Lula teve como política moderada, com ruptura moderada, visando alcançar a confiança internacional e investimento privado (BOITO Jr., 2007). A confiança era vinculada à figura do vice-presidente, e, também, de empresários como Roberto Rodrigues (presidente da Associação Brasileira de Agrobusiness (ABAG) e Luiz Fernando Furlan (presidente do Conselho de Administração da Sadia), além de outros vários empresários a ocupar alguma pasta ministerial. Lula produziu um insistente diálogo com o setor empresarial, o que permitiu ao seu governo construir canais de acesso com o setor produtivo via articulações políticas. Essa aproximação com o empresariado manifestava-se não apenas pelo contato com José Alencar na vice-presidência, mas também pela indicação de outros empresários em sua base ministerial, e, sobretudo, pela maior presença da classe no Congresso Nacional.

Quanto à avaliação do setor empresarial ao governo Lula, as decisões tomadas no primeiro mandato não foram uniformes. No entanto, para o então diretor-executivo do Instituto de Estudos para o Desenvolvimento Industrial (IEDI), Júlio Sérgio Gomes, o governo procurou recuperar a ideia de empresariado nacional e seu papel no desenvolvimento industrial brasileiro. Segundo Diniz e Boschi (2007), é possível identificar três tipos de avaliações quanto aos primeiros anos do mandato do governo Lula. Em primeiro lugar, quanto aos empresários que acreditavam que o governo seria muito ruim, descumprindo acordos do FMI e contratos internacionais, a gestão foi vista como um alívio por essa parte da classe. Agora, para aqueles empresários ligados ao IEDI, não houve surpresas, pois acreditavam que Lula não tomaria atitudes radicais; no entanto, viram, a rigor, na postura do governo, excesso de cautela. "Entre o medo e a esperança, o governo teria preferido o primeiro. Ademais, o IEDI avalia equivocada a orientação que combina câmbio valorizado e juros altos" (DINIZ; BOSCHI, 2007, p. 80). O terceiro grupo identificado, representado pelas orientações mais tradicionais, como a Confederação Nacional da Indústria (CNI), era preciso adotar uma perspectiva mais matizada. Nos aspectos negativos, criticavam as altas taxas de juros, porém incentivavam os esforços de política industrial e de estímulo ao comércio exterior. Também adotavam postura de abertura 
ao diálogo com o empresariado. A crítica consensual fora no sentido de minimizar o chamado custo Brasil, reduzindo a carga tributária e o custo do trabalho.

O vínculo com os interesses do grande capital financeiro se mantém por meio do Ministério da Fazenda e do Banco Central, que "[...] se constituem nos locais privilegiados nesse esquema de concentração do poder na definição da política econômica” (BOITO Jr., 2007. p.68). Entretanto, no que diz respeito ao empresariado nacional, as mudanças tiveram um forte impacto em suas articulações no Executivo, ampliando sua relação com o governo e permitindo uma maior atuação da classe. Apesar do modelo de desenvolvimentismo adotado se mostrar favorável a alguns segmentos empresariais, a classe foi cautelosa na candidatura do presidente em 2006. "Embora pronunciamentos individuais tenham sido raros, foi possível, porém, identificar um grupo de apoio ao Presidente Lula, com Ivo Rosset, Presidente da Valisère, Lawrence Pih, Presidente do Moinho Pacífico, e Michel Haradom” (DINIZ; BOSCHI, 2007, p. 128). O dirigente do instituto Ethos, Oded Granjew, apesar de manifestar apoio à candidatura, construiu duras críticas com relação à conduta ética da gestão Lula. O empresário Eugênio Staub, presidente da empresa Gradiente e conselheiro do IEDI, não se manifestou a favor de Lula. Para ele, o governo foi demasiadamente conservador na execução da política econômica. O empresário Ivoncy Ioschpe, presidente do grupo Ioschpe-Maxion e conselheiro do IEDI, manifestou a mesma opinião de Staub, afirmando que o modelo vigente era a expressão de um modelo que se esgotara.

Quanto ao financiamento da campanha, segundo o jornal Folha de S. Paulo, Lula teria recebido doações dos setores financeiro, da construção civil e de grandes empreiteiras. $\mathrm{O}$ candidato de oposição, Geraldo Alckmin (PSDB), teria recebido doações individuais de grandes empresas brasileiras, como a Gerdau, a CSN e a Votorantin, além de contar com o apoio do setor de agronegócio. E, embora existam indícios de que a maioria dos empresários paulistas tenha manifestado apoio à candidatura Alckmin, o mesmo não se confirmou no restante do país.

O segundo mandato do governo Lula foi marcado pela crise de 2008. A repercussão da crise no Brasil, ao contrário do proposto pelas políticas neoliberais, levou a uma forte intervenção do Estado na economia. Com medidas de incentivo ao consumo e intenso apoio aos setores mais atingidos, o governo usou de instrumento de intervenção a de valorização da Petrobrás, BNDES, Banco do Brasil e Caixa Econômica Federal, dando a esperança necessária para o país atravessar a crise no curto prazo. Potencializando fissuras na hegemonia da fração bancário-financeira, em comparação com outros segmentos, como de commodities e de parte da indústria nacional, passou-se à recuperação em termos absolutos. Alguns autores apontam 
esse período como um novo desenvolvimentismo no Brasil, denominando de "neodesenvolvimentismo" ou "social-desenvolvimentismo".

O discurso da ampliação da presença do Estado na economia brasileira, durante a campanha eleitoral de 2010, silenciou grande parte do empresariado. Este se mostrou muito temoroso em manifestar apoio a algum candidato. Segundo o presidente da CNI, deputado federal pelo PTB, Armando Monteiro, isso ocorreu porque “[...] os empresários são realistas. Nesta sucessão presidencial, não há um candidato de perfil nitidamente liberal. Não existe esta opção. [...] É possível supor que Serra, se eleito, fará uma gestão fiscal mais austera. Mas não há temores com nenhum dos dois" (ISTOÉ, 2010, p. 1). Entretanto, existiram exceções com relação a essa postura, como o empresário Abílio Diniz, presidente do Conselho de Administração do Grupo Pão de Açúcar, que apoiou a candidata petista, afirmando que Dilma “[...] tem todas as condições de levar adiante o legado deixado [...]. É o legado do crescimento, da geração do emprego e da distribuição de renda. Este é o legado que ele (Lula) deixa" (O Globo, 2010, p.1). Cláudio Conz, empresário ligado à construção civil e representante do Conselho de Desenvolvimento Econômico e Social (CDES), declarou total apoio ao governo do PT, mantendo o apoio a Dilma. A candidata do PT venceu o pleito contra José Serra (PSDB), com $56,05 \%$ dos votos no segundo turno.

Logo no início do primeiro mandato de Dilma, o governo anunciou a redução da taxa de juros, revelando uma mudança nas relações entre o sistema financeiro e o Estado brasileiro. A iniciativa pressionava instituições privadas a reduzir seus ganhos. Houve, nesse período de 2010/2012, um impulso pela demanda, baseado no crescimento interno e na redistribuição de renda, com alguns incentivos a determinados setores. Essa elevação do consumo das famílias não levou a um dinamismo industrial, devido ao vazamento da renda para o exterior com o aumento das importações de manufaturas. A consequência foi a redução do efeito multiplicador das políticas sociais e do salário mínimo (SINGER, 2015). O setor privado apresentava sinais de enfraquecimento, atraindo a atenção do governo para a capacidade dos setores industriais em obterem investimento.

Alguns ensaios já definiram o governo Dilma como uma tentativa de retomar o crescimento econômico, por meio de políticas de cunho desenvolvimentista, de perfil socialdesenvolvimentista, tentando dar continuidade ao trabalho do governo Lula. No entanto, o cenário do mandato de Lula foi totalmente diferente do de Dilma, revelando, num futuro mais recente, o fracasso do seu plano de desenvolvimento e o afastamento da classe empresarial como base aliada do governo. A política do governo combinava equacionar um crescimento econômico sob a liderança de indústria, por meio de uma forte intervenção estatal, em que o 
objetivo era minimizar os problemas sociais, estabelecendo um amplo canal de diálogo com o setor produtivo e a classe trabalhadora. O problema residia, contraditoriamente, na acumulação financeira e no alto rentismo brasileiro. A esse respeito, Singer (2015) afirma que Dilma, ao tentar mexer na base do rentismo para dar sequência à nova matriz econômica, gerou no capital bancário e financeiro temor quanto à sua política de governo.

As análises de alguns economistas ajudam a compreender os erros do governo Dilma. Dentre as interpretações apresentados por Singer (2015), uma resposta estaria na condição estrutural da burguesia industrial de hoje, que é fragilizada pela coalização produtivista desde a origem. Setores produtivos e financeiros se atrelam a atividades puramente rentistas, valendose dos investimentos seguros com elevada liquidez. Outra linha apresenta o caráter da luta de classes, com a elevação do emprego e do nível de salários. Toda vez que o estado sustenta o pleno emprego, a burguesia usaria da greve de investimentos como forma de não perder seu poder de decisão. A terceira explicação refere-se ao papel da ideologia dominante, no tocante à classe empresarial brasileira. Na quarta análise, coloca-se a importância das forças internacionais no processo de decisão interna. E, por fim, ressalta-se que as políticas de Dilma eram movidas pelo interesse público, ferindo os interesses privados e do capital. Quatro anos após sua posse, o governo já não contava mais com a base aliada da grande maioria dos empresários, o que seguido da perda de base política, ainda que com apoio de parte do eleitorado.

\section{Participação e ação política do empresariado catarinense}

Com a ascensão da indústria em Santa Catarina, revelou-se necessário uma estrutura sindical que representasse a classe patronal no estado. Para suprir tal necessidade, surge a Federação das Indústrias do Estado de Santa Catarina (FIESC), órgão de representação mais amplo do empresariado industrial catarinense. Foi fundada apenas no ano de 1950, quando no cenário nacional a estrutura de representação corporativa já estava instalada desde a década de 1930. O motivo do aparente atraso na mobilização do empresariado pode estar associado a uma indústria pouco relevante ao nível nacional, além da ação política ser menos dinâmica no estado (GÜNTS, 2006).

Uma breve análise da FIESC mostra que entender sua organização é imprescindível para compreender o comportamento da classe empresarial de Santa Catarina. A FIESC ocupa um papel central como interlocutor do governo e do empresariado, sendo entidade chave na relação entre Estado e esfera privada. Desde a sua fundação, seus dirigentes mantiveram uma colaboração muito estreita com as autoridades governamentais. A Federação é a organização 
de ponta do empresariado industrial, sendo a mais influente junto à sociedade civil e às instâncias públicas. Tem principalmente poder em controlar recursos importantes, com o lema do desenvolvimento industrial em Santa Catarina.

Por meio da entidade, o empresariado catarinense buscou representar eficazmente suas demandas junto aos poderes Executivo e Legislativo, em nível estadual e federal. "Os contatos entre a FIESC e os governos estaduais teriam sido bastante próximos já desde a sua fundação, chegando a certos momentos a um processo de osmose entre as duas esferas, dificultando a percepção dos menos avisados quanto à linha divisória entre o que é público e o que é privado" (GÜNTHS, 2006, p.2).

A Federação representa uma agenda ativa no que diz respeito às políticas econômicas e industriais, formulando e desenvolvendo análises, indicadores e padrões de opinião junto ao empresariado estadual. Sua força de representação é evidenciada não apenas por ser uma entidade tradicional, mas, principalmente, pelo alcance de suas ações. "Sendo composta por mais de 50 mil empresas, nas quais trabalham mais de 800 mil pessoas, sendo responsável por um terço da riqueza gerada em solo catarinense" (FIESC, 2016, p. 1). Observando a trajetória da estrutura corporativa, percebe-se que a evolução foi contínua ao longo das décadas, e hoje é constituída por 141 sindicatos, representando uma das federações de indústrias com o maior número de entidades filiadas em todo o país, abrangendo aproximadamente 6,5 mil indústrias associadas (FIESC, 2016).

O Quadro 1 apresenta resumidamente o histórico dos presidentes à frente da FIESC. Observa-se que Celso Ramos foi o representante da direção por 12 anos, intercalando em alguns momentos com a vida pública. Bernardo Wolfgang Werner foi o presidente com mais tempo na direção da FIESC, permanecendo por 15 anos seguidos. Milton Fett ficou à frente da Federação por 6 anos, e, atualmente, Glauco Corte está na presidência por duas gestões consecutivas.

A entidade foi fundada por sete sindicatos industriais, sediados em Florianópolis. A primeira diretoria foi formada essencialmente por representantes das indústrias de madeira, têxtil e produtos transformados. Seu primeiro presidente e coo-fundador, Celso Ramos, industrial do ramo de madeira da região de Lages, e familiar de importantes políticos de representatividade nacional, manteve o mandato da instituição durante seis anos. $\mathrm{O}$ fato de Florianópolis concentrar o poder público, assegurou à cidade uma posição de destaque dentro da Federação. Além disso, na década de 1950, o eixo de poder econômico concentrava-se especialmente em três regiões: Vale do Itajaí, Florianópolis e Joinville, sendo essas três as 
principais regiões a ocupar o cargo da presidência desde sua fundação até os dias atuais (GÜNTS, 2006).

Quadro 1 - Presidentes da Federação das Indústrias do Estado de Santa Catarina (FIESC): $1950-2017$

\begin{tabular}{|l|c|c|l|}
\hline \multicolumn{1}{|c|}{ Presidente } & Gestão & $\begin{array}{c}\text { Segmento } \\
\text { Empresarial }\end{array}$ & Cidade \\
\hline Celso Ramos & $1950-1960 / 1964-1966$ & Madeireira & Florianópolis \\
\hline Guilherme Renaux & $1962-1966$ & Têxtil & Blumenau \\
\hline Carlos Cid & $1968-1971$ & Têxtil & Blumenau \\
\hline Bernardo Wolfgang Werner & $1971-1986$ & Metalurgia & Blumenau \\
\hline Milton Fett & $1986-1992$ & Madeireira & Florianópolis \\
\hline Osvaldo Douat & $1992-1999$ & Têxtil & Joinville \\
\hline José Fernando Xavier Faraco & $1999-2005$ & Tecnologia & Florianópolis \\
\hline Alcantaro Corrêa & $2005-2011$ & Metalurgia & Blumenau \\
\hline Glauco José Côrte & $2011-2017$ & Cerâmica & Florianópolis \\
\hline
\end{tabular}

Fonte: Elaborado pelos autores a partir de dados coletados no portal FIESC (2016)

Embalada pelas altas taxas de crescimento econômico, a indústria catarinense deslanchou na década de 1970, tornando-se líder nacional em carne de aves e suínos, refrigeradores, motores elétricos, tubos e conexões de PVC e revestimentos cerâmicos. A conduta da Federação nesse período ressaltou a importância da união entre governo e empresa privada para o desenvolvimento do país. Sob direção de Bernardo Werner, a federação propôs a criação da Secretaria Estadual da Indústria e Comércio. A proximidade entre público e privado se mantinha com a participação de diretores da FIESC nos governos do estado, seja em conselhos ou em cargos na Secretaria do Planejamento.

Conhecida por ser uma classe conversadora, o empresariado catarinense se viu dividido no período da redemocratização no país. Com interesse nos cargos eletivos, a divisão do empresariado ficava a cargo do melhor partido e candidato a representá-los. Desse modo, a Federação consolidou-se como centro de uma disputa patronal no meio empresarial catarinense, sendo até os dias atuais a instituição de representação mais importante da classe empresarial no estado.

O período de 1992 a 1995 pode ser interpretado como a era do PFL (Partido da Frente Liberal) na FIESC. Isso porque o então presidente da Federação, Osvaldo Douat, ocupava o cargo de assessor profissional do senador Vilson Kleinubing, eleito governador pelo PFL. Durante todo o governo de Kleinubing (1990-1994), a FIESC assumiu indiretamente a direção 
da Secretaria de Indústria e Comércio de Santa Catarina. Conforme Günts (2006), do total de 52 dirigentes que compunham a diretoria da Federação na gestão 1992-95, 23 dirigentes da Federação estariam filiados a um partido político, principalmente ao PPB e ao PFL. No ano de 1992, a entidade criou o Centro Internacional de Negócios e o Conselho Político Industrial, composto por 28 dirigentes empresariais, entre eles Luiz Fernando Furlan (na época presidente da Sadia, e que viria ser Ministro do Desenvolvimento, Indústria e Comércio Exterior do governo Lula). Nesse mesmo ano foi lançado o Projeto Estratégico de Desenvolvimento Industrial de Santa Catarina, em parceria com a Secretaria Estadual da Fazenda (FIESC, 2016).

Ao fim da década de 1990, a FIESC já detinha o poder de definição da política industrial no estado. Para tanto, colocava à “"[...] disposição do governo, sua estrutura para a realização de seminários, debates, convenções, reuniões, para definições de estratégias e planos de ação em relação ao desenvolvimento do Estado" (GÜNTS, 2006, p.32). A partir do governo de Espiridião Amin (1999/2002), a temática do desenvolvimento é operacionalizada por meio dos Fóruns Regionais de Desenvolvimento, ato que consolida o retorno da FIESC ao Executivo do estado. No ano de 2001 a FIESC firma parceria com o Instituto Ehtos de Empresas e Responsabilidade Social, com o intuito de difundir "[...] boas práticas e políticas responsáveis na gestão dos negócios junto ao empresariado catarinense. Propõe a criação do Fórum Sul de Energia" (FIESC, 2016, p.17).

A década de 2000 marca um compromisso da Federação pelo alcance da competividade. Sob a gestão de Alcantaro Corrêa, a FIESC assegurou, juntamente à Petrobras, o cumprimento dos contratos de fornecimento de gás natural às indústrias do estado. No mesmo ano, a Federação liderou o Conselho das Federações Empresariais de Santa Catarina (COFEM) com o intuito de barrar o aumento do Imposto sobre Circulação de Mercadorias e Serviços (ICMS). Tal conselho contava com a liderança de seis entidades: Federação da Agricultura do Estado de Santa Catarina (FAESC), Federação das Associações Comerciais e Industriais (FACISC), Federação das Associações de Micro e Pequenas Empresas (FAMPESC), Federação das Câmaras de Dirigentes Lojistas (FCDL), Federação do Comércio (FECOMÉRCIO) e Federação das Empresas de Transporte de Cargas (FETRANCESC).

Com uma visão mais ligada às questões ambientais, a indústria catarinense buscou adequar-se às normas da Federação com o desenvolvimento sustentável, de modo que a FIESC, em 2006, desenvolveu o documento "Pacto Federativo como Instrumento do Desenvolvimento Sustentável". Entre os principais tópicos do documento estava o fortalecimento da fiscalização através dos órgãos municipais e da Fundação do Meio Ambiente (FATMA). Buscando adequarse aos tratados e acordos internacionais em torno do meio ambiente, a FIESC promove 
encontros, seminários, discussões, workshops e capacitações sobre o assunto, e elabora pareceres técnicos e pesquisas, entre outros suportes ao empresariado. Nesse sentido, em parceria com a CNI e o Serviço Nacional de Aprendizagem Industrial (SENAI), a entidade lança o Programa Mercado de Carbono, com o objetivo de inserir as indústrias do estado no mercado global de carbono. Como resultado, Santa Catarina é um dos estados que tem mais projetos de mecanismo de desenvolvimento limpo no país (FIESC, 2016).

Conforme relatório sobre a Política Catarinense de Ciência, Tecnologia e Inovação, desenvolvido pela Secretaria de Estado do Desenvolvimento Econômico Sustentável, a FIESC, por meio do Instituto Euvaldo Lodi (IEL), é a entidade responsável pelo desenvolvimento de serviços que favoreçam o aperfeiçoamento empresarial. As ações são divididas em áreas como capacitação, educação e estágio, oferecendo à indústria o suporte técnico para estimular inovação, eficiência em gestão e treinamentos em sintonia com a nova ordem econômica mundial.

A respeito da pressão da classe na esfera governamental, foi elaborado um relatório sobre perspectivas do desenvolvimento catarinense. O documento foi lançado antes das eleições para governo do estado de 2006. Alcantaro Corrêa cobrou dos então candidatos o cumprimento da agenda proposta. Dentre os candidatos que consentiram com as medidas, estava o vencedor do pleito, Luiz Henrique da Silveira (PMDB). No ano seguinte, quando o governo decidiu aumentar as alíquotas de ICMS do estado, a FIESC possuía argumentos para defender os interesses do empresariado. A Federação lançou então um manifesto contra a prorrogação da Contribuição Provisória sobre Movimentação Financeira (CPMF). Junto com a entidade, os demais integrantes do Conselho das Federações Empresariais de Santa Catarina (COFEM) também assinaram o manifesto. Como medida de persuasão, a FIESC instala em sua sede um banner com o nome dos parlamentares que votaram a favor da renovação da CMPF. Em respeito ao compromisso que havia assumido, o governo recuou na decisão. Segundo a FIESC esse foi um ganho para a sociedade catarinense, além do que, para a classe empresarial, era um alivio na carga tributária.

A entidade elaborou em 2008 uma proposta de mudança na legislação para aumentar a participação de Santa Catarina nos royalties do Pré-Sal. O relatório chegou à conclusão de que o Projeto de Lei no Senado Federal no 279/08, da Senadora Ideli Salvatti (PT), era favorável ao estado, uma vez que, modificando a extensão dos limites dos estados na Plataforma Continental, traria mais benefícios ligados à arrecadação de royalties. A Federação sugeriu, ainda, buscar apoio junto à comunidade política e empresarial para estender alterações no Projeto de Lei $n^{\circ}$ 279/08 (FIESC, 2016). 
No ano de aniversário de 60 anos da entidade, a FIESC lança o "Projeto Desenvolvimento SC - uma visão da indústria”. O documento contava com a perspectiva de apresentar pautas da indústria, incorporando diversas reivindicações empresariais. O intuito do documento era servir como um mapa estratégico para que os candidatos a governador do estado formulassem seu programa de campanha, assim como orientassem suas ações para o futuro. "Queremos que essa abertura de diálogo com os candidatos não pare na entrega deste documento. Por isso propomos uma sólida parceria, que envolve construirmos juntos, os setores público e privado, um projeto de desenvolvimento para Santa Catarina. Este é apenas o primeiro passo" (Alcantaro Corrêa, 2010, p. 3).

A entidade acredita que, se a indústria tiver voz ainda mais ativa na definição de políticas do estado, toda a sociedade ganhará. O relatório contou com a visão do empresariado sobre Santa Catarina, pautando dez áreas crucias que deveriam passar por transformações estruturais, sendo elas: Infraestrutura, Racionalização Tributária, Educação, Inovação e Modernização, Representação Política, Políticas de Desenvolvimento, Exportações, Meio Ambiente, Relações de Trabalho e Governança para o Desenvolvimento. Conta ainda com sete objetivos estratégicos a serem alcançados: Competitividade internacional da indústria, Retenção e atração de empresas, Adensamento de cadeias produtivas, Diversificação e novos setores, Integração do estado, Economia em harmonia com o meio ambiente, Epicentro logístico. Para tanto seria necessário um alinhamento dessas expectativas com as esferas pública e privada.

A FIESC não acredita em intervencionismo ou dirigismo estatal, mas crê na eficácia das forças de mercado como geradoras de riquezas. Cabe ao estado prover as condições estruturais de competitividade para que o setor privado cumpra a sua parte, em benefício de todos. A Federação segue o posicionamento das diretrizes da CNI, onde se defende o Estado mínimo na economia, visando melhores resultados para a classe. Por isso, trabalha ativamente em proporcionar um ambiente menos burocrático para incentivar a produção e a competividade industrial.

A gestão de Glauco Corte se faz atuante no cenário nacional, combatendo medidas que considera prejudiciais à classe empresarial, como cortes tributários, aumentos na carga energética e reformas trabalhistas. Em vista disso, a Federação conduz suas ações a fim de alcançar suas metas diante de adversidades impostas pelo aparelho estatal, chegando a distribuir pelo estado campanhas em outdoor para influenciar a sociedade civil a participar de sua causa (exemplo: campanha contra aumento do ICMS), e fortalecendo ações nacionais contra a desindustrialização. Como se pode observar no Quadro 2, as medidas institucionais da Federação caminham com a preocupação do empresariado nacional, buscando proporcionar ao 
ambiente interno recursos necessários para o crescimento do setor. Portanto, há a preocupação de levar o nome do estado para todo o mundo, na perspectiva de obter do setor exportador impulso ao aumento da produtividade industrial catarinense.

O Programa de Desenvolvimento Industrial Catarinense (PDIC) se transformou na formulação de uma política industrial para o estado e referência das ações da FIESC, numa visão de curto, médio e longo prazo. O PDIC pretende identificar as visões de futuro de cada setor, traçando caminhos para atingir o desenvolvimento industrial. "Trata-se de um programa de múltiplas iniciativas, conectadas no sentido de potencializar o desenvolvimento da indústria estadual, numa articulação entre empresas, governo, terceiro setor e instituições de ensino" (FIESC, PDIC 2022, 2016, p. 1). Para isso o programa visa induzir uma dinâmica industrial de longo prazo, posicionando a indústria como protagonista do desenvolvimento do estado.

Pensando no longo prazo e no futuro da indústria em Santa Catarina, a Federação lançou em 2014 o plano estratégico para 2022. Na apresentação do Plano Estratégico, o presidente Glauco Côrte afirmou que, entre 2012 e 2014, a visão da Federação estava voltada à ampliação dos serviços e da integração operacional entre as entidades. Os esforços da FIESC se concentrariam na qualidade, racionalização e eficiência do setor industrial. O plano atualiza as diretrizes nas áreas de ambiente institucional, qualidade de vida, educação e inovação tecnológica.

Segundo a teoria de que a política cria a possibilidade de manobra e movimento, o partido político é um canal de acesso para tal ação, e, assim, é de interesse observar a filiação da diretoria da atual gestão para compreender o pensamento ideológico de suas ações de classe. $\mathrm{O}$ estreito contato com o setor público é uma forma de persuasão do empresariado industrial pela busca de seus interesses. Empresários, por vezes, fazem da filiação partidária um modo de articulação política. Adotando, por hipótese, a ideia de que se filiar a um partido significa aderir à ideologia do partido, e também ter o direito de se lançar como candidato numa eleição, analisar a filiação da diretoria da FIESC se faz pertinente. Assim, foi tomada como referência a filiação dos membros da diretoria da FIESC na gestão 2014-2018. Os dados, apresentados na tabela 1, foram levantados no portal do Tribunal Superior Eleitoral. 
Quadro 2 - Principais ações realizadas pela Federação das Indústrias do Estado de Santa Catarina (FIESC): 2011 a 2015

\begin{tabular}{|c|c|}
\hline Ano & Ação \\
\hline \multirow{5}{*}{$\overline{\vec{i}}$} & $\begin{array}{l}\text { O Conselho das Federações Empresariais junto do governador Raimundo Colombo assinaram o pacto pela } \\
\text { competitividade. }\end{array}$ \\
\hline & $\begin{array}{l}\text { Criação do Comitê Estratégico para Logística Reversa, Comitê de Mineração e novos presidentes para as } \\
\text { Câmaras Tributária, Construção, Energia, Panificação, Transporte logística e Têxtil. }\end{array}$ \\
\hline & $\begin{array}{l}\text { Participou em Brasília, ao lado da CNI, do Plantão Legislativo para mostrar os projetos que impactam na } \\
\text { competitividade da indústria. }\end{array}$ \\
\hline & $\begin{array}{l}\text { Lançamento da Agenda Legislativa, Desempenho e Perspectivas da Indústria, Diagnóstico do Setor } \\
\text { Exportador, Guia da Indústria, Santa Catarina em Dados e o Sistema FIESC: um olhar para o futuro } \\
\text { catarinense. }\end{array}$ \\
\hline & $\begin{array}{l}\text { Entregou ao ministro de Ciência, Tecnologia e Inovação, pedido de apoio para o projeto PLATIC II } \\
\text { (Plataforma de Tecnologia da Informação e Comunicação de Santa Catarina). }\end{array}$ \\
\hline \multirow{5}{*}{$\frac{2}{\stackrel{c}{\sim}}$} & $\begin{array}{l}\text { Por meio do Fórum Estratégico da Indústria Catarinense, realizou dois encontros para debater temas } \\
\text { prioritários para o desenvolvimento do Estado e da indústria, como educação, tributação, } \\
\text { desindustrialização, investimentos, infraestrutura e competitividade. }\end{array}$ \\
\hline & $\begin{array}{l}\text { Instituído o Conselho de Economia, órgão colegiado, de natureza consultiva para a entidade no } \\
\text { posicionamento de assuntos relacionados à competitividade. }\end{array}$ \\
\hline & Realizou dois encontros em Brasília para definir estratégias de desenvolvimento para o estado. \\
\hline & Reuniu os deputados estaduais e a bancada federal, para lançamento da Agenda Legislativa da Indústria. \\
\hline & $\begin{array}{l}\text { Promoveu encontros de integração com a Associação dos Magistrados Catarinenses (AMC), com o } \\
\text { Ministério Público de Santa Catarina e com o Tribunal Regional do Trabalho (TRT/SC). }\end{array}$ \\
\hline \multirow{5}{*}{ 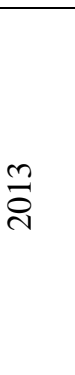 } & Lançamento do PDIC - Programa de Desenvolvimento Industrial Ca \\
\hline & Criação da Assessoria de Comunicação e Marketing (Comar). \\
\hline & $\begin{array}{l}\text { Manteve contato constante com o ministro do Trabalho, mobilizando pela aprovação do projeto de lei que } \\
\text { regulamentaria a terceirização e pelo fim da multa extra de } 10 \% \text { do FGTS. }\end{array}$ \\
\hline & $\begin{array}{l}\text { Representantes do COFEM e das centrais sindicais laborais entregaram ao governador Raimundo Colombo } \\
\text { proposta de consenso para atualizar o piso regional de SC. }\end{array}$ \\
\hline & $\begin{array}{l}\text { Em parceria com o movimento Todos pela Educação promoveu o intercâmbio e a cooperação sobre o tema } \\
\text { para o compartilhamento de conhecimentos e a transferência de experiências. }\end{array}$ \\
\hline \multirow{5}{*}{$\frac{ \pm}{\sigma}$} & $\begin{array}{l}\text { Foram realizadas } 100 \text { ações entre reuniões, cursos e encontros, dos quais participaram presidentes e } \\
\text { secretários-executivos dos } 139 \text { sindicatos de indústria filiados. }\end{array}$ \\
\hline & $\begin{array}{l}\text { Entregou aos candidatos ao governo e ao Senado, a Carta da Indústria, documento que listava os principais } \\
\text { entraves ao crescimento econômico do Estado, propondo } 126 \text { ações de melhoria. }\end{array}$ \\
\hline & $\begin{array}{l}\text { Por meio do Fórum Parlamentar Catarinense reforçou a atuação conjunta da FIESC e dos deputados } \\
\text { federais e senadores. A infraestrutura foi eleita como prioritário para o desenvolvimento do Estado. }\end{array}$ \\
\hline & $\begin{array}{l}\text { O Programa de Desenvolvimento Industrial Catarinense (PDIC 2022) apresentou as rotas de crescimento } \\
\text { para diversos setores. Mais de } 1,7 \text { mil lideranças e especialistas de todo o estado debateram o futuro dos } \\
\text { segmentos agroalimentar, cerâmica, construção civil, economia do mar, energia, indústrias emergentes, } \\
\text { metalmecânico, metalurgia, móveis e madeira, plástico, químico, tecnologia da informação e comunicação, } \\
\text { têxtil e confecção e saúde. }\end{array}$ \\
\hline & Fórum Industrial Sul, formado pela FIESC, FIEP e FIERGS, confirmou a demanda por mais gás na região. \\
\hline \multirow{5}{*}{$\frac{n}{\stackrel{n}{c}}$} & Campanha da FIESC valorizou os parlamentares que votaram a favor da terceirização. \\
\hline & $\begin{array}{l}\text { Fórum Parlamentar Catarinense reforçaram a defesa de uma agenda para criar um ambiente favorável à } \\
\text { retomada da economia e evitar qualquer medida que aumente a carga tributária. }\end{array}$ \\
\hline & $\begin{array}{l}\text { Atuou junto à Agência Nacional de Energia Elétrica (ANEEL) contra a elevação nas tarifas de energia } \\
\text { elétrica no estado. }\end{array}$ \\
\hline & $\begin{array}{l}\text { As Câmaras especializadas e os Comitês acompanharam de perto as mudanças na área tributária e em } \\
\text { legislações estaduais e federais. }\end{array}$ \\
\hline & $\begin{array}{l}\text { Com outdoors em todas as regiões do estado, foi realizada campanha contra o retorno da Co } \\
\text { Provisória sobre Movimentação Financeira (CPMF). }\end{array}$ \\
\hline
\end{tabular}

Fonte: Elaborado pelo autor a partir de dados coletados no portal FIESC (2016) 
Tabela 1 - Número de filiações partidárias na diretoria da Federação das Indústrias do Estado

\begin{tabular}{|c|c|}
\hline Partido Político & $\mathrm{N}^{0}$ de filiações partidárias \\
\hline Partido Progressista (PP) & 7 \\
\hline Partido Social Democrático (PSD) & 4 \\
\hline Democratas (DEM) & 2 \\
\hline Partido Democrático Trabalhista (PDT) & 2 \\
\hline Partido da Social Democracia Brasileira (PSDB) & 2 \\
\hline Partido Popular Socialista (PPS) & 1 \\
\hline Partido da República (PR) & 1 \\
\hline Partido Socialista Brasileiro (PSB) & 1 \\
\hline Total de filiações & 20 \\
\hline
\end{tabular}

Fonte: Elaborado pelos autores a partir de dados coletados no site do Tribunal Superior Eleitoral

Dos 66 membros da diretoria, contando com vice-presidentes regionais, vice-presidentes de assuntos estratégicos, diretores, membros do conselho fiscal e delegação junto à CNI, 20 deles possuem uma filiação partidária. Vemos que o partido com maior número de filiações é o Partido Progressista (PP), mostrando a forte influência histórica do partido dentro da Federação.

No gráfico da Figura 1, vemos os dados distribuímos por percentual das filiações. O Partido Progressista (PP) e o Partido Social Democrático (PSD) somam 55\% do total de filiações da diretoria. O Democratas (DEM), o Partido Democrático Trabalhista (PDT) e o Partido da Social Democracia Brasileira (PSDB) somam, juntos, 30\% das filiações. O Partido Popular Socialista (PPS), o Partido da República (PR) e o Partido Socialista Brasileiro (PSB) atingem, juntos, $15 \%$ das filiações.

Figura 1 - Filiações partidárias na diretoria da Federação das Indústrias do Estado de Santa Catarina (FIESC) - Gestão 2014-2018

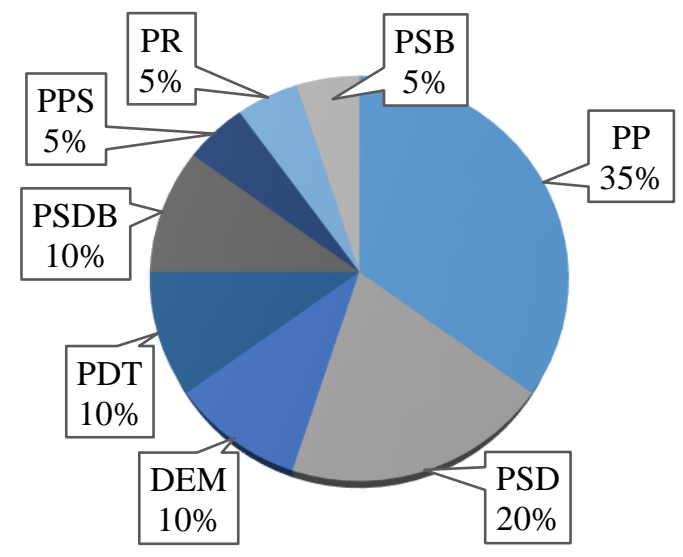

$$
\begin{aligned}
& \square \mathrm{PP} \\
& \text { - PSD } \\
& \square \mathrm{DEM} \\
& \square \mathrm{PDT} \\
& \square \mathrm{PSDB} \\
& \square \mathrm{PPS} \\
& \square \mathrm{PR} \\
& \square \mathrm{PSB}
\end{aligned}
$$

Fonte: Elaborado pelos autores a partir de dados coletados no site do Tribunal Superior Eleitoral (2016) 
O Estado de Santa Catarina possui 7 regiões principais de concentração industrial. A FIESC está presente em cada região, através de suas 16 vice-presidências regionais. Juntamente com os vice-presidentes de cada regional, a FIESC conta ainda com a presença de 25 diretores. Em sua grande maioria, são presidentes de algum sindicato patronal. A representação é muito importante nesse processo, para fazer políticas estratégicas de desenvolvimento regional. Nos termos de Gramsci (2006), o vínculo orgânico entre os intelectuais e a classe social que eles representam aparece nas atividades que exercem no seio das sociedades civil e política. No gráfico da Figura 2, abaixo, pode-se observar a Filiação sindical dos diretores da FIESC na gestão de 2014-2018.

Figura 2 - Filiação sindical dos diretores da Federação das Indústrias do Estado de Santa Catarina (FIESC) - Classificação por região estadual - Gestão 2014-2018

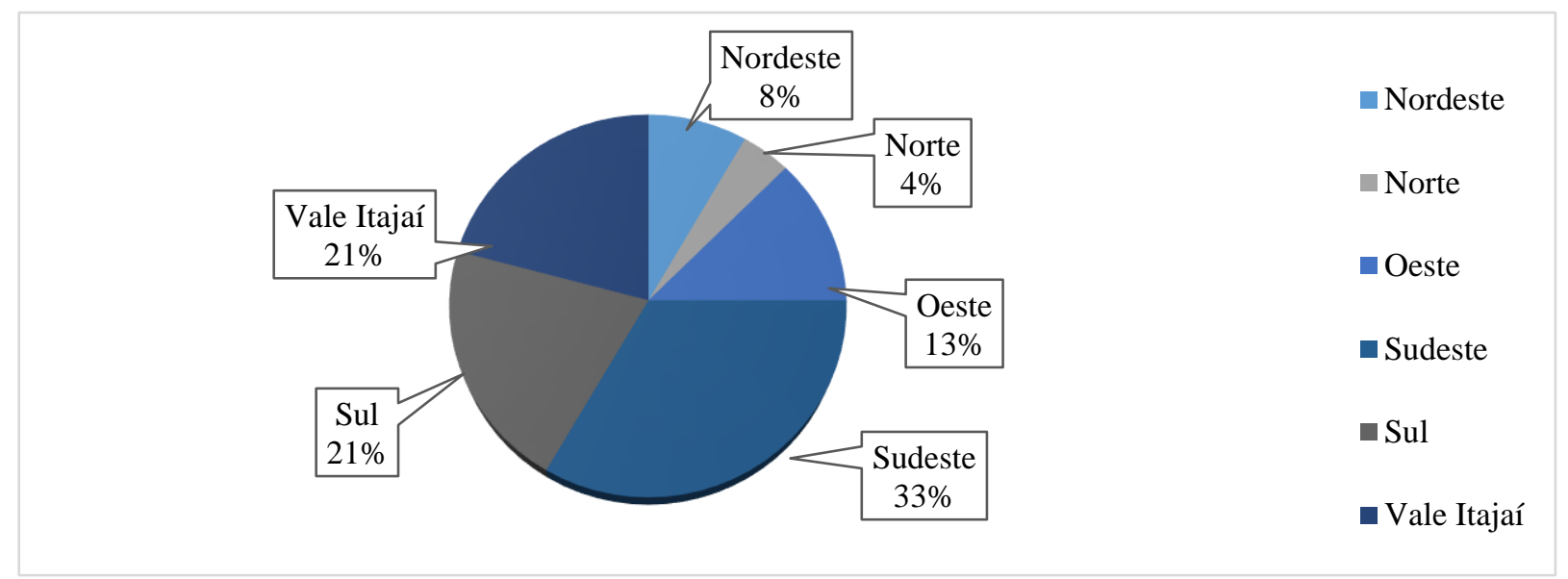

Fonte: Elaborado pelos autores a partir de dados coletados no portal FIESC (2016)

Observa-se aqui a predominância de representação na região Sudeste, onde, dos 25 membros diretores da Federação, 33\% são representantes de algum sindicato patronal da região, seguida do Sul e do Vale do Itajaí, ambos com 21\%. Com menor percentual seguem o Oeste, com $13 \%$, o Nordeste, com $8 \%$, e, por fim, o Norte, com 4\%, regiões essas menos atuantes no processo decisório da FIESC.

No Quadro 3 podemos visualizar os membros diretores que possuem uma filiação partidária, o sindicato patronal coligado e a região atuante. 
Quadro 3 - Filiação partidária e sindical dos diretores da Federação da Indústrias do Estado de Santa Catarina (FIESC) - Gestão 2014-2018

\begin{tabular}{|c|c|c|c|}
\hline Nome & Sindicato & Partido & Região \\
\hline $\begin{array}{c}\text { Bretzke } \\
\text { Henrique de Bastos } \\
\text { Malta }\end{array}$ & Sindicato das Indústrias da Alimentação de Jaraguá \\
do Sul & PDT & Vale do Itajaí \\
\hline José Sylvio Ghisi & $\begin{array}{c}\text { Sindicato da Indústria da Construção Civil do Sul } \\
\text { Catarinense }\end{array}$ & PDT & Sul \\
\hline Osni Carlos Verona & $\begin{array}{c}\text { Sindicato da Indústria Madeireira e Moveleira do } \\
\text { Vale do Uruguai }\end{array}$ & DEM & Oeste \\
\hline Osório Dal Bello & $\begin{array}{c}\text { Sindicato da Indústria de Carnes e Derivados de } \\
\text { Santa Catarina }\end{array}$ & PP & Sudeste \\
\hline $\begin{array}{c}\text { Pedro Leal da Silva } \\
\text { Neto }\end{array}$ & Sindicato Patronal Têxtil de Rio do Sul & PSD & Vale do Itajaí \\
\hline $\begin{array}{c}\text { Rogério Pedro } \\
\text { Mendes }\end{array}$ & $\begin{array}{c}\text { Sindicato das Indústrias Metalúrgicas, Mecânicas e } \\
\text { Material Elétrico de Caravaggio }\end{array}$ & PR & Sul \\
\hline Walgenor Teixeira & $\begin{array}{c}\text { Sindicato das Industrias Gráficas de } \\
\text { Rio do Sul }\end{array}$ & PP & Vale do Itajaí \\
\hline Wanderley Zunino & $\begin{array}{c}\text { Sindicato dos Trabalhadores nas Indústrias de } \\
\text { Calçados de São João Batista }\end{array}$ & PPS & Sudeste \\
\hline
\end{tabular}

Fonte: Elaborado pelo autor a partir de dados coletados no portal FIESC (2016)

Como os diretores das regiões Norte e Nordeste não possuem filiação partidária, não constam do quadro. A região Oeste possui um diretor coligado ao DEM. A região Sudeste possui uma filiação ao DEM, uma ao PP e uma PPS. A região Sul possui uma filiação ao PDT e outra ao PR. No Vale do Itajaí, há uma ao PDT, uma ao PP e uma ao PSD. A diversificação é composta por 6 partidos, mas em nenhuma das regiões se constatou mais de dois filiados ao mesmo partido.

\section{Conclusão}

Levando em consideração que o Estado brasileiro é uma das pontas do tripé do desenvolvimento nacional, trabalhar em conjunto com a classe empresarial é um desafio particular a ser atendido. Como estratégia do empresariado, cabe articular-se conjuntamente para se fortalecer como classe e, por meio de ações, influenciar a esfera governamental. Conforme a visão de que desenvolvimento das forças produtivas ocorre no espaço econômico e político, a FIESC procurou, ao longo da sua história, usar as relações ideológicas como uma forma de controlar as relações de produção da indústria através do seu poder de influência na sociedade.

Segundo Poulantzas (1978), a inserção de uma ideologia dominante na sociedade ocorre por meio dos aparelhos ideológicos do Estado. Nessa esfera, podem ser representados por associações de classe, como é o caso da FIESC. Tendo na reprodução do capital uma forma de 
relação social subordinada ao ciclo produtivo e da luta de classes, estabelecer no seio do Estado um espaço de ação ideológica permitiu a essa federação uma postura de agente decisório no processo de decisão, sobretudo no que diz respeito às políticas econômicas em favorecimento da classe no estado. Como classe, seus integrantes polarizam alguns dos seus interesses específicos, transformando seus próprios interesses econômicos em interesses políticos. Exemplos disso são os pactos acordados com chefes de governo, pela competividade do setor e pela redução dos custos trabalhistas.

A entidade lutou ativamente pelo alcance de sua representatividade, fortalecendo a cada diretoria o contato com o setor público. Em diversas gestões, seus membros também tinham particular influência no estado, seja de maneira direta como chefe de estado, ocupando cargos em secretárias e conselhos ou ainda por meio da filiação partidária. Conforme a teoria de Gramsci, referido no início do artigo, o partido político cumpre um importante papel na sociedade, pois exerce uma função orgânica no seio do Estado. A entidade firmou importante vínculo com determinados partidos políticos, e, hoje, mais de $30 \%$ das filiações da diretoria é ligada ao Partido Progressista (PP).

Desenvolvendo relatórios sobre política industrial a ser colocada em prática, e participando de projeto de desenvolvimento, a instituição conquista atenção junto à esfera federal. Mas, além da condução política de suas ações, a FIESC buscou, por meio de todos os serviços ofertados, conduzir suas demandas para as demais classes da sociedade. Encabeçou campanhas contra aumentos tributários e levou o nome da indústria catarinense para outros países, por meio de suas iniciativas em comércio exterior. Também presta serviço de política econômica para o governo do estado, assim como é atuante com as diretrizes da CNI. Mais ainda, capacita industriais e trabalhadores, por meio de cursos profissionalizantes e palestras, além de estabelecer, na última gestão, uma aproximação com o ambiente universitário, seja por meio de pesquisas e estudos colaborativos, seja também pela inserção de novos profissionais no mercado de trabalho. Suas atuais demandas visam a inovação, gerando competitividade para a indústria, em contexto no qual a desindustrialização representa uma das principais pautas de preocupação.

Posto isto, a Federação consolida-se como o mais importante canal de representação entre o empresariado industrial e o governo. Estabelecendo diálogo com âmbito federal e estadual, a instituição dá confiança aos seus filiados. Portanto, a FIESC desempenha um papel central para a organização dos interesses de classe, devido à sua forte estrutura corporativa. 


\section{Referências}

BOITO JUNIOR, A. Estado e burguesia no capitalismo neoliberal. Revista de Sociologia e Política, $\mathrm{n}$. 28, p. 57-73, 2007. Obtido em: <http://www.scielo.br/pdf/rsocp/n28/a05n28.pdf > . Acesso em: 16 nov. 2016.

CARNOY, M. Estado e teoria política. Campinas: Papirus, 1988.

CORRÊA, Alcantaro. Desenvolvimento de Santa Catarina: uma visão da indústria. Florianópolis: FIESC, 2010.2 Obtido em: $<$ http://www2.fiescnet.com.br/web/uploads/recursos/8977715556b8506e6fb8b92617f9aaa2.pdf>. Acesso em: 7 nov. 2016.

DINIZ, E.; BOSCHI, R. R. A difícil rota do desenvolvimento: empresários e a agenda pósneoliberal. Belo Horizonte: Editora UFMG, 2007.

DINIZ, E.; BOSCHI, R. Globalização, herança corporativa e representação dos interesses empresariais: novas configurações no cenário pós-reformas. In: BOSCHI, R.; DINIZ, E.; SANTOS, F. Elites políticas e econômicas no Brasil contemporâneo. São Paulo: Fundação Konrad Adenauer, 2000, p. 15-88.

DINIZ, E. Empresário, Estado e capitalismo no Brasil: 1930-1945. Rio de Janeiro: Paz e Terra, 1978.

DRAIBE, S. M. Rumos e metamorfoses: Estado e industrialização no Brasil 1930-1960. Rio de Janeiro: Paz e Terra, 2004.

DREIFUSS, R. A. A elite orgânica: recrutamento, estrutura e organização para ação. In: 1964: A conquista do Estado: ação política, poder e golpe de classe. 3.ed.. Petrópolis: Vozes, 1981, p.161227.

DREIFUSS, R. A. Brevíssimas anotações conceituais sobre "Elites orgânicas". In: A Internacional Capitalista. Rio de Janeiro:Espaço e Tempo, 1987, p. 21- 31.

FELIX, J. De que lado estão os empresários? Pela primeira vez, capitães da indústria terão que votar em um candidato que defende o aumento do papel do Estado e ninguém está com medo. IstoÉ. São Paulo, p. 13-14. 05 mar. 2010. Obtido em: $<$ http://istoe.com.br/55202_DE+QUE+LADO+ESTAO+OS+EMPRESARIOS+/>. Acesso em: 07 nov. 2016.

FEDERAÇÃO DAS INDÚSTRIAS DO ESTADO DE SANTA CATARINA. A força da indústria catarinense. Florianópolis: FIESC, 2016. Obtido em: <http://fiesc.com.br/>. Acesso em: 21 nov. 2016.

GRAMSCI, A. Os intelectuais. O princípio educativo. Jornalismo. In: Cadernos do cárcere. Rio de Janeiro: Civilização Brasileira, 2006, p.7-53.

GÜNTHS, Marisa Larsen. A ação política do empresariado industrial catarinense: o caso da FIESC Federação das Indústrias do Estado de Santa Catarina. In: WORKSHOP EMPRESA, EMPRESÁRIOS E SOCIEDADE, 5.ed., Porto Alegre: FEE, 2006. p. 1 - 46. Disponível em: $<$ http://www.fee.rs.gov.br/5workshop/pdf/gt02_marisa.pdf $>$. Acesso em: 16 nov. 2016.

MANCUSO, W. P. O empresariado como ator político no Brasil: balanço da literatura e agenda de pesquisa. Revista de Sociologia e Política, n. 28, p.131-146, 2007. Obtido em: http://dx.doi.org/10.1590/s0104-44782007000100009. Acesso em: 07 nov. 2016

MELLO, J. M. C. de. O capitalismo tardio. Campinas: Instituto de Economia/UNICAMP, 1998.

O GLOBO. Abilio Diniz declara apoio a Dilma. 2010. Obtido em: $<$ http://oglobo.globo.com/politica/abiliodiniz-declara-apoio-dilma-3044413>. Acesso em: 07 nov. 2016

POULANTZAS, N. O Estado, o poder, o socialismo. Rio de Janeiro: Graal, 1978.

SINGER, A. Cutucando onças com varas curtas: o ensaio desenvolvimentista no primeiro mandato de Dilma Rousseff (2011-2014). Novos Estudos, v. 102, p.43-71, 2015. 